\title{
Dynamin 2 is required for GPVI signaling and platelet hemostatic function in mice
}

Haematologica 2020

Volume 105(5):1414-1423

\section{Correspondence: \\ HERVÉ FALET \\ hfalet@versiti.org \\ Received: February 19, 2019. \\ Accepted: July 9, 2019. \\ Pre-published: July 11, 2019.}

doi:10.3324/haematol.2019.218644

Check the online version for the most updated information on this article, online supplements, and information on authorship \& disclosures: www.haematologica.org/content/105/5/1414

(C)2020 Ferrata Storti Foundation

Material published in Haematologica is covered by copyright. All rights are reserved to the Ferrata Storti Foundation. Use of published material is allowed under the following terms and conditions:

https://creativecommons.org/licenses/by-nc/4.0/legalcode. Copies of published material are allowed for personal or internal use. Sharing published material for non-commercial purposes is subject to the following conditions:

https://creativecommons.org/licenses/by-nc/4.0/legalcode, sect. 3. Reproducing and sharing published material for commercial purposes is not allowed without permission in writing from the publisher.

\author{
Nathan Eaton, ${ }^{1,2}$ Caleb Drew, ${ }^{1}$ Jon Wieser, ${ }^{1}$ Adam D. Munday, ${ }^{3,4}$ \\ and Hervé Falet ${ }^{1,2}$ \\ ${ }^{1}$ Blood Research Institute, Versiti, Milwaukee, WI; 'Department of Cell Biology, \\ Neurobiology, and Anatomy, Medical College of Wisconsin, Milwaukee, Wl; ${ }^{3}$ Bloodworks \\ Northwest Research Institute, Seattle, WA and ${ }^{4}$ Division of Hematology, Department of \\ Medicine, University of Washington, Seattle, WA, USA
}

\section{ABSTRACT}

$\mathrm{R}$ eceptor-mediated endocytosis, which contributes to a wide range of cellular functions, including receptor signaling, cell adhesion, and - migration, requires endocytic vesicle release by the large GTPase dynamin 2 . Here, the role of dynamin 2 was investigated in platelet hemostatic function using both pharmacological and genetic approaches. Dnm $2^{n / m}$ Pf4-Cre (Dnm $\left.2^{\text {Plt- }}\right)$ mice specifically lacking dynamin 2 within the platelet lineage developed severe thrombocytopenia and bleeding diathesis and $D n m 2^{P l t r}$ platelets adhered poorly to collagen under arterial shear rates. Signaling via the collagen receptor GPVI was impaired in platelets treated with the dynamin GTPase inhibitor dynasore, as evidenced by poor protein tyrosine phosphorylation, including that of the proximal tyrosine kinase Lyn on its activating tyrosine 396 residue. Platelet stimulation via GPVI resulted in a slight decrease in GPVI, which was maintained by dynasore treatment. Dynasore-treated platelets had attenuated function when stimulated via GPVI, as evidenced by reduced GPIb $\alpha$ downregulation, $\alpha$-granule release, integrin $\alpha I \mathrm{Ib} \beta 3$ activation, and spreading onto immobilized fibrinogen. By contrast, responses to the G-protein coupled receptor agonist thrombin were minimally affected by dynasore treatment. GPVI expression was severely reduced in $D n m 2^{P h-1}$ platelets, which were dysfunctional in response to stimulation via GPVI, and to a lesser extent to thrombin. Dnm2 $2^{P t-1}$ platelets lacked fibrinogen in their $\alpha$-granules, but retained von Willebrand factor. Taken together, the data show that dynamin 2 plays a proximal role in signaling via the collagen receptor GPVI and is required for fibrinogen uptake and normal platelet hemostatic function.

\section{Introduction}

Receptor-mediated endocytosis (RME), the process by which cells internalize and sort specific extracellular material, plasma membrane proteins, and lipids, contributes to a wide range of cellular functions, including receptor signaling, cell adhesion, and migration. ${ }^{1}$ RME requires membrane fission by the large and ubiquitous GTPase dynamin 2 (DNM2), which polymerizes at the neck of budding endocytic vesicles to mediate the GTP-dependent membrane fission required for their release into the cytosol prior to their incorporation into the endosomal compartment. ${ }^{2}$ Consistent with its indispensable role in cellular homeostasis, DNM2 mutations have been associated with Charcot-Marie-Tooth disease, centronuclear myopathy, and early T-cell precursor acute lymphoblastic leukemia (ETP-ALL), ${ }^{3 \cdot 5}$ and Dnm2 deletion results in early embryonic lethality in mice. ${ }^{6}$ While other classical dynamins (DNM1 and DNM3) are critical for activity-dependent vesicle recycling in presynaptic neurons, ${ }^{7,8}$ their functions in other cells remain less clear.

The most well-characterized physiological roles of RME are to regulate uptake of nutrients such as cholesterol and iron and to down-modulate cytokine receptor signaling. ${ }^{1}$ Lack of DNM2-dependent RME enhances responses to thrombopoietin in platelets and megakaryocytes (MK), ${ }^{9}$ and to epidermal growth factor and inter- 
leukins 5 and 7 in other cells, ${ }^{10-12}$ the proposed mechanism associating DNM2 loss-of-function mutations and ETPALL development. ${ }^{5}$ Further, previous studies using pharmacological approaches have suggested that dynamin GTPase activity contributes to receptor desensitization in human platelets, as in the case of the purinergic receptors P2Y1 and P2Y12. ${ }^{13}$

Human platelets express all three classical dynamins, ${ }^{14,15}$ including an inactive DNM3 spliced variant, for which a single nucleotide polymorphism has been associated with platelet size. ${ }^{16}$ In comparison, mouse platelets express predominantly the ubiquitous DNM2 ${ }^{14,17}$ thus providing a valuable model to study DNM2-dependent RME in platelet and MK biology, independent of neuronal DNM1 and DNM3. We have previously shown that Dnm2 $2^{f / l l}$ Pf4Cre $\left(D n m 2^{P t-1-}\right)$ mice specifically lacking DNM2 in the platelet lineage develop severe macrothrombocytopenia due to membrane fission arrest and accumulation of clathrin-coated vesicles obstructing the MK demarcation membrane system, the highly organized membrane reservoir for future platelets. ${ }^{9}$ Here we investigated the role of DNM2 in platelet hemostatic function using both pharmacological and genetic approaches. Our data show that DNM2 regulates proximal signaling via the platelet collagen receptor GPVI and that DNM2-dependent RME is required for the accumulation of plasma fibrinogen into $\alpha$-granules to facilitate normal platelet hemostatic function.

\section{Methods}

\section{Mice}

$D n m 2^{P l t-1}$ mice were described previously. ${ }^{9}$ Mice were treated according to the National Institutes of Health and Medical College of Wisconsin Institutional Animal Care and Use Committee guidelines.

\section{Platelet count}

Platelet count was measured on a Sysmex XT-2000i automatic hematology analyzer using blood collected by mouse retroorbital plexus bleeding and immediately diluted in Cellpack (Sysmex) supplemented with EDTA and PGE1. ${ }^{18}$

\section{Tail bleeding time}

Bleeding time was determined by snipping $2 \mathrm{~mm}$ of distal mouse tail and immediately immersing the tail in $37^{\circ} \mathrm{C}$ isotonic saline. ${ }^{19}$ A complete cessation of bleeding was defined as the bleeding time.

\section{Ex vivo perfusion assay}

Platelet interaction with immobilized type I collagen was performed using the VenaFlux Platform and Vena8Fluor+ biochips (Cellix). ${ }^{20}$ Additional information can be found in the Online Supplementary Methods.

\section{Platelet preparation and flow cytometry}

Blood was collected by mouse retro-orbital plexus bleeding and was anticoagulated in acid-citrate-dextrose. ${ }^{19}$ Platelets were isolated by sequential centrifugation, resuspended at $5 \times 10^{8}$ platelets $/ \mathrm{mL}$, and incubated for 30 minutes (min) at $37^{\circ} \mathrm{C}$ with $100 \mu \mathrm{M}$ of the non-competitive inhibitor of dynamin GTPase activity, dynasore (EMD Millipore), ${ }^{13,21-23}$ or vehicle $(0.1 \%$ DMSO).

Platelets were activated or not with collagen-related peptide
Table 1. Primary antibodies used.

\begin{tabular}{llcc} 
Target & Host & Type & Company \\
pTyr (4G10 Platinum) & Mouse & Monoclonal & EMD Millipore \\
pLyn (Y396) & Rabbit & Monoclonal & Boster Biological \\
\hline Lyn & Mouse & Monoclonal & Santa Cruz \\
DNM2 & Mouse & Monoclonal & Santa Cruz \\
\hline$\beta$-actin & Rabbit & Polyclonal & Abcam \\
$\beta$-tubulin & Mouse & Monoclonal & Sigma-Aldrich \\
\hline GPVI (JAQ1) & Rat & Monoclonal & Emfret Analytics \\
GPIb $\alpha$ (CD42b) & Rat & Monoclonal & Emfret Analytics \\
\hline P-selectin (CD62P) & Rat & Monoclonal & BD Biosciences \\
$\alpha$ IIb (CD41) & Rat & Monoclonal & R\&D Systems \\
\hline Fibrinogen & Rabbit & Polyclonal & DAKO \\
vWF & Rabbit & Polyclonal & DAKO \\
\hline Clathrin Heavy Chain & Mouse & Monoclonal & EMD Millipore \\
Cavin 2 (SDPR) & Rabbit & Polyclonal & Proteintech \\
\hline Caveolin 1 & Rabbit & Monoclonal & Cell Signaling \\
Rab5 & Rabbit & Monoclonal & Cell Signaling \\
\hline Rab7 & Rabbit & Monoclonal & Cell Signaling \\
Rab11 & Rabbit & Monoclonal & Cell Signaling \\
\hline Flotillin 1 & Mouse & Monoclonal & BD Biosciences \\
\hline
\end{tabular}

pTyr: phosphotyrosine; pLyn: phosphorylated Lyn; vWF: von Willebrand factor.

(CRP; Protein Chemistry Core Laboratory, Blood Research Institute, Versiti, USA) or human thrombin (Roche) for 2-3 min at $37^{\circ} \mathrm{C}$ and stained with FITC-labeled rat anti-mouse GPIb $\alpha$ or FITC-labeled rat anti-mouse P-selectin antibodies (Table 1) or Oregon Green 488-labeled fibrinogen (Thermo Fisher Scientific). ${ }^{19}$ Fluorescence was quantified using an Accuri C6 flow cytometer (BD Biosciences) and FlowJo software. A total of 10,000 events were analyzed for each sample.

\section{Immunoblot analysis}

Platelets were lysed as described. ${ }^{19}$ Platelet proteins were separated by SDS-PAGE, transferred onto an Immobilon-P membrane (EMD Millipore), and probed with antibodies directed against proteins of interest (Table 1). Platelet fibrinogen content was quantitated using purified mouse fibrinogen (Enzyme Research) as standard.

Lipid rafts were isolated from human platelets as described. ${ }^{24}$ Blood was collected from volunteers by venipuncture and was anticoagulated in acid-citrate-dextrose. Approval was obtained from the Western Institutional Review Board and informed consent was approved according to the Declaration of Helsinki.

\section{Immunofluorescence microscopy}

Samples were imaged on Nikon Structured Illumination Microscopy (N-SIM, NIS-Elements AR v4.40.00 software) and Olympus Confocal FV1000-MPE (FluoView software) platforms under 100x oil objectives. ${ }^{9,25}$ Additional information can be found in the Online Supplementary Methods.

\section{Statistical analysis}

All experiments were performed at least in triplicate. Results were compared with the unpaired Student $t$-test (simple), twoway ANOVA followed by Bonferroni correction (multiple), or the Kaplan-Meier analysis (time-to-event) using Prism software (GraphPad). $P<0.05$ was considered significant. 


\section{Results}

\section{Hemostatic defects in Dnm2 $2^{\text {Plt-- }}$ mice}

$D n m 2^{P l t-r}$ mice developed severe thrombocytopenia, with $152 \pm 15 \times 10^{3}$ platelets/uL [mean \pm standard error of mean SEM); $\mathrm{n}=15]$, compared to $1,299 \pm 54 \times 10^{3}$ platelets/ $\mu \mathrm{L}$ in control Dnm $2^{2 / / 1 / 4}$ mice $(\mathrm{n}=18)(P<0.0001)$, an $88 \%$ reduction (Figure $1 \mathrm{~A}$ ), as described previously. ${ }^{9}$ The role of DNM2 in platelet hemostatic function was evaluated using the tail bleeding time assay (Figure 1B). Control mice had a median tail bleeding time of $1.16 \mathrm{~min}$. By contrast, Dnm2 $2^{P_{1-1}-}$ mice had a profound bleeding diathesis with all mice studied bleeding for $10 \mathrm{~min}$, our experimental end-point measurement ( $\mathrm{n}=12$ in each group) (Log-rank $P<0.0001$.

Following blood vessel injury and disruption of the vascular endothelium, platelets are exposed to basement membrane proteins and soluble agonists, which initiate platelet adhesion and activation, leading to thrombus formation and preventing excessive bleeding. At arterial shear rates, initial platelet adhesion is mediated by collagen-bound von Willebrand factor (vWF) binding to the GPIb-IX complex, followed by platelet activation via the collagen receptor GPVI. ${ }^{26}$ The functionality of $D n m 2^{P^{p t-1}}$ platelets in whole blood was tested in flow chamber experiments using the VenaFlux platform ${ }^{20}$ where binding to a collagen-coated surface was measured under arterial shear rate $\left(1500 \mathrm{~s}^{-1}\right)$ to mediate the interaction of plasma vWF with surface-bound collagen (Figure 1C-F). After 4 min, control platelets covered $18.0 \pm 5.1 \%($ mean \pm SEM; $\mathrm{n}=7$ ) of the collagen-coated surface (Figure 1E). Adhesion was markedly decreased in $D n m 2^{P h-1}$ platelets, with only $0.6 \pm 0.1 \%(n=4)(P=0.0333)$ of surface coverage, a $97 \%$ reduction.

The dwell time of individual control and $D n m 2^{P^{P h-1}}$ platelets was analyzed under the same experimental conditions (Figure 1F). After initial tethering, control platelets dwelled for a median time of 61 seconds $(s) \quad(n=60)$. $D n m 2^{P h-}$ platelets dwelled for a significantly lower median time of $33 \mathrm{~s}(\mathrm{n}=61)$ (Log-rank $P=0.0331)$, indicating that a decreased stability of the GPIbo-vWF interaction contributes to the poor adhesion of $D n m 2^{\text {Plt- }-}$ platelets to collagen under arterial shear rates and the profound bleeding diathesis of $D n m 2^{P(t-1}$ mice.

\section{Impaired GPVI signaling in dynasore-treated and Dnm2 ${ }^{\text {Plt- }-}$ platelets}

Collagen binding to its platelet receptor GPVI initiates a signaling pathway that sequentially involves activation of the Src family tyrosine kinases Fyn and Lyn, phosphorylation of the GPVI-associated FcR $\gamma$-chain, and recruitment, tyrosine phosphorylation, and activation of the tyrosine kinase Syk, leading to activation of phospholipase C- $\gamma 2$ (PLC- $\gamma 2){ }^{27}$ The ability of DNM2 to regulate GPVI signaling was investigated (Figure 2). Control platelets, platelets treated with $100 \mu \mathrm{M}$ dynasore to inhibit DNM2 GTPase activity pharmacologically, and $D n m 2^{P_{t h-}}$ platelets were activated with the GPVI agonist CRP. In control platelets,
A

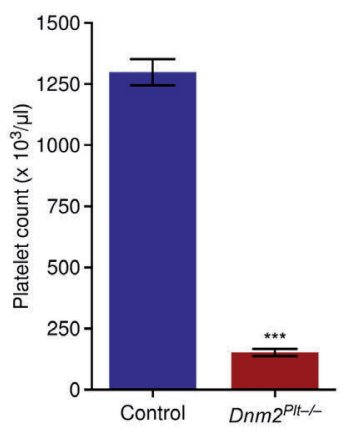

D

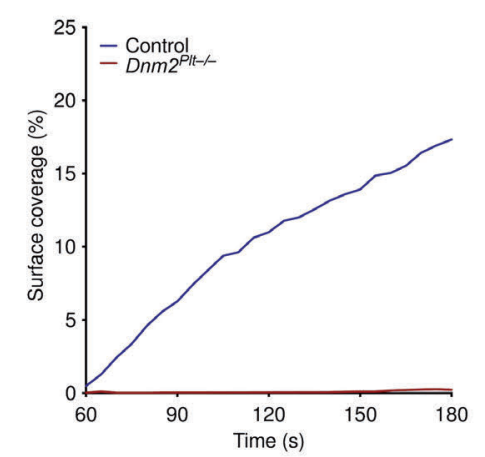

B

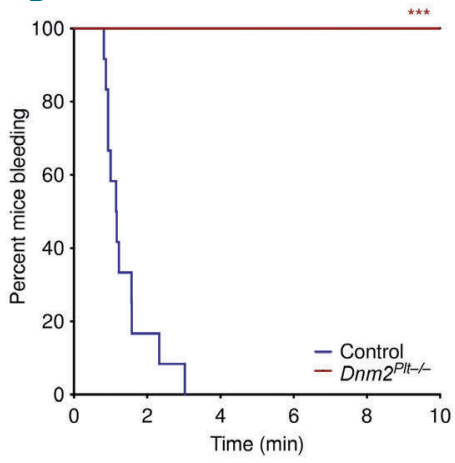

E

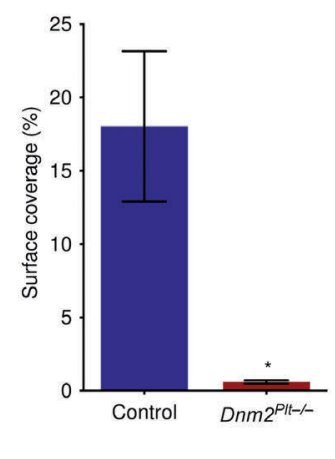

C
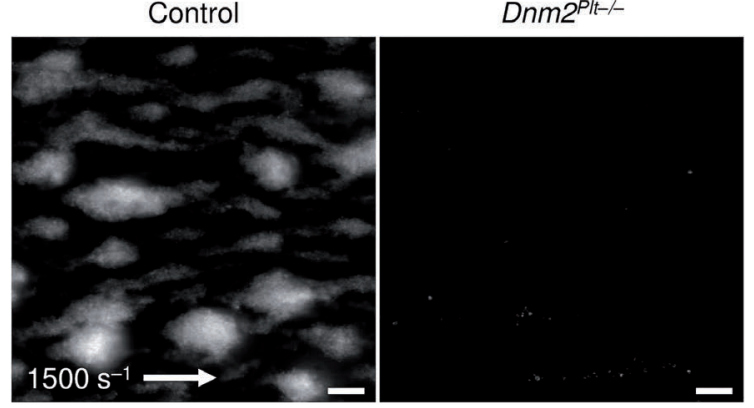

$\mathrm{F}$

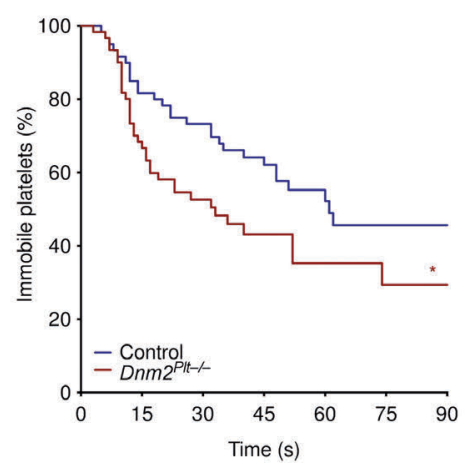

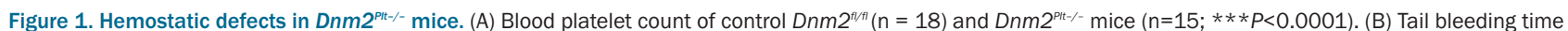
of control Dnm2 $2^{f / f l}$ and Dnm2 $2^{p t-/-}$ mice ( $n=12$ in each group; Log-rank $\left.* * * P<0.0001\right)$. (C-F) PPACK-anticoagulated whole blood from control and Dnm2 $2^{f / f l}$ mice was labeled and perfused on type I collagen-immobilized surface at an arterial shear rate of $1500 \mathrm{~s}^{-1}$. (C) Representative still image at 4 min. Scale bars, $100 \mu \mathrm{m}$. (D) Representative time-course surface coverage, as labeled platelets accumulate in the field of view. (E) Surface coverage at 4 min (mean \pm SEM; 7 control and 4

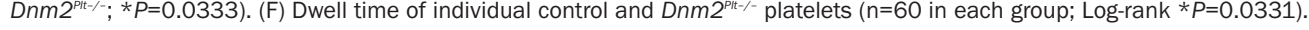


CRP stimulation induced tyrosine phosphorylation of several proteins, including proteins at $125,72,68,56,52$, and $38 \mathrm{kDa}$ (Figure 2A). Dynasore-treated platelets had a moderate reduction of tyrosine phosphorylation of these proteins in response to CRP stimulation, and $D n m 2^{P l t-1}$ platelets failed to increase protein tyrosine phosphorylation, even at high doses of CRP.

Because of its proximal role in the GPVI signaling pathway, ${ }^{28}$ Lyn activation was probed using an antibody specifically directed against its phosphorylated activating tyrosine 396 (Tyr396) residue (Figure 2B). Stimulation of control platelets with CRP induced a $62 \pm 19 \%$ increase in Lyn Tyr396 phosphorylation that peaked at $2.5 \mu \mathrm{g} / \mathrm{mL}$ CRP (mean \pm SEM; $n=3$ in each group) $(P=0.0408)$. Lyn Tyr396 phosphorylation was attenuated in dynasoretreated platelets and markedly reduced in Dnm $2^{P l t-/}$ platelets.

GPVI expression in control, dynasore-treated, and $D n m 2^{P t-1-}$ platelets was further evaluated by immunoblot analysis using the monoclonal antibody JAQ1 (Figure 2C). Following stimulation of control platelets with 25 $\mu \mathrm{g} / \mathrm{mL}$ CRP, JAQ1 signal decreased by $15 \%$, compared to resting levels. Dynasore treatment resulted in a $10 \%$ increase in JAQ1 signal, which was maintained following CRP stimulation. Taken together, the data show that
DNM2 contributes to GPVI homeostasis at rest and GPVI downregulation and Lyn activation following GPVI ligation. As reported previously, GPVI expression was markedly decreased in Dnm $2^{P l t-1}$ platelets, ${ }^{9}$ and was unaffected by CRP.

\section{Impaired GPIb $\alpha$ downregulation in CRP-stimulated dynasore-treated and Dnm2 $2^{\text {Plt-- }}$ platelets}

GPIb $\alpha$ is internalized during platelet activation, ${ }^{29}$ a phenomenon that is expected to negatively affect initial platelet adhesion to collagen-bound vWF and for which a role of dynamin has been reported, based on pharmacological inhibition. ${ }^{22}$ The role of DNM2 in this process was investigated in response to the GPVI agonist CRP or the soluble G-protein-coupled receptor agonist thrombin (Figure 3). Expression of surface GPIb $\alpha$ decreased to about $30 \%$ of resting levels following stimulation of control platelets with CRP (Figure 3A) or thrombin (Figure 3B).

In response to stimulation with $\mathrm{CRP}$, expression of surface GPIb $\alpha$ decreased to $60 \%$ of resting levels in dynasoretreated platelets, a $50 \%$ reduction compared to controls, and $D n m 2^{P t-/}$ platelets failed to down-regulate GPIb $\alpha$ (Figure 3A). By contrast, dynasore treatment or Dnm2 deletion did not affect GPIb $\alpha$ downregulation when platelets were stimulated with thrombin (Figure 3B).
A

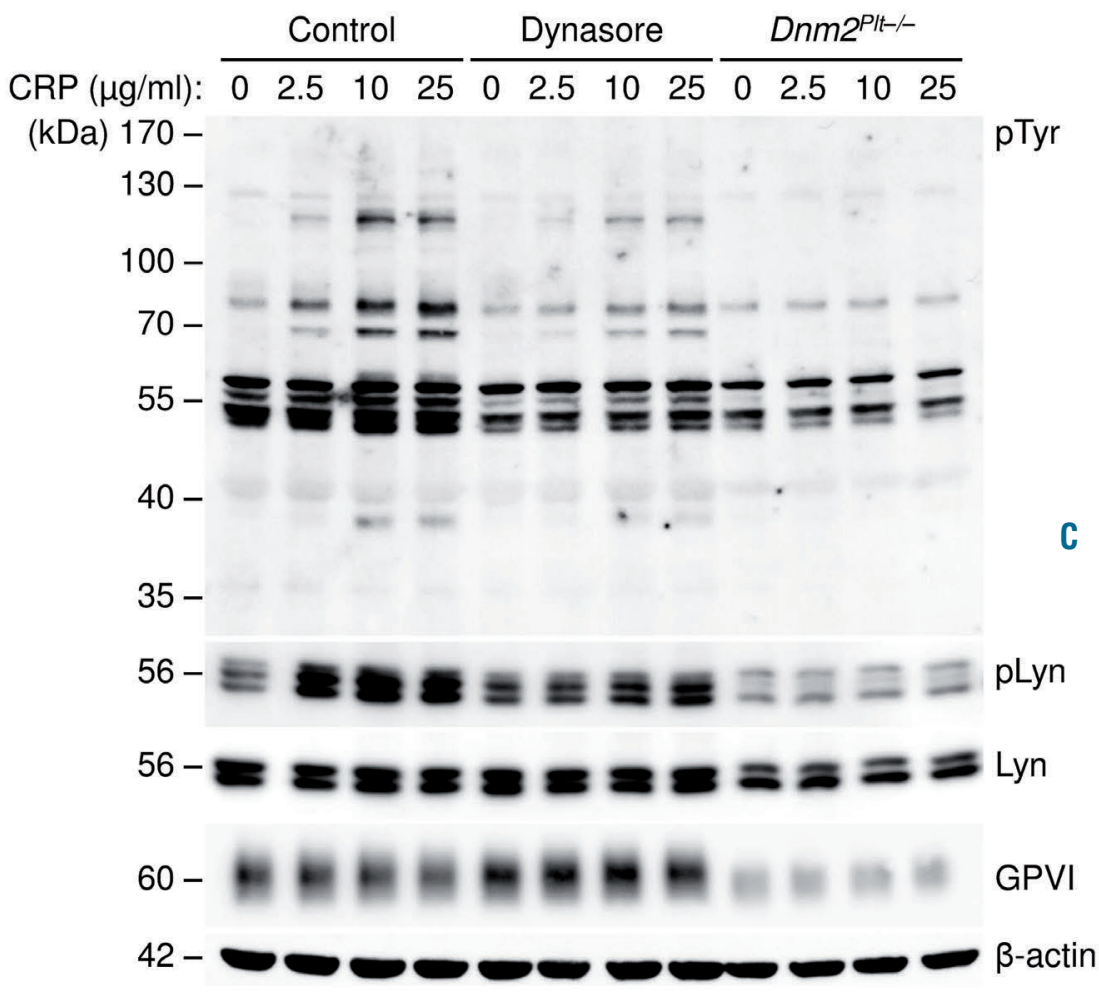

B

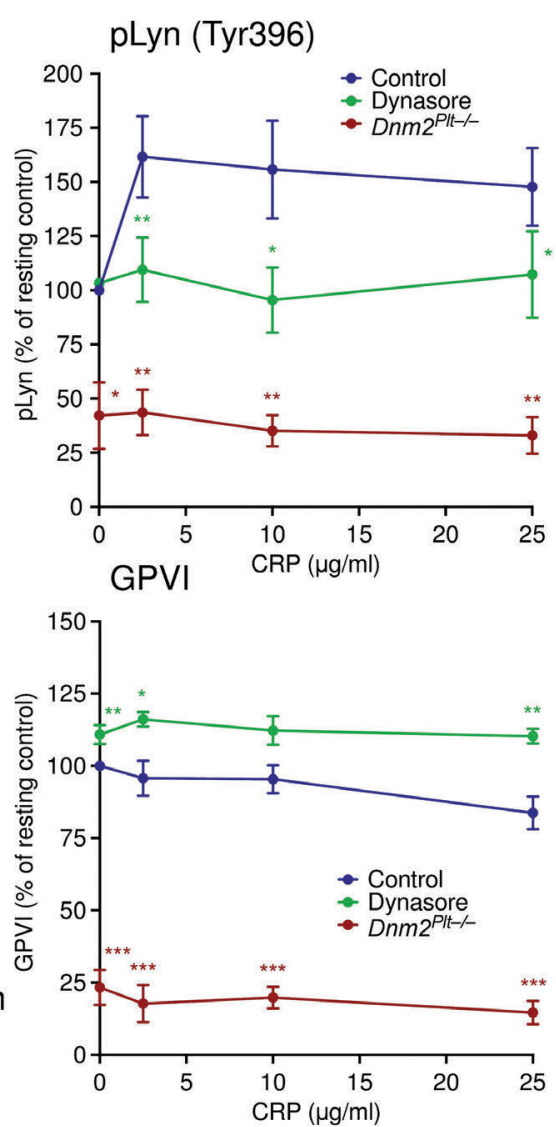

Figure 2. GPVI signaling defects in dynasore-treated and Dnm2 $2^{\text {Ptt- } /-}$ platelets. Control platelets, platelets treated with $100 \mu \mathrm{M}$ dynasore, and $D n m 2^{\text {Ptt- } /-}$ platelets were activated or not with CRP for 2 minutes at $37^{\circ} \mathrm{C}$ as indicated. (A) Platelet lysates corresponding to $2 \mu g$ of protein were subjected to SDS-PAGE and probed for phosphotyrosine (pTyr), phosphorylated Lyn Tyr396 (pLyn), Lyn, GPVI, and $\beta$-actin as a loading control. Results are representative of five independent experiments.

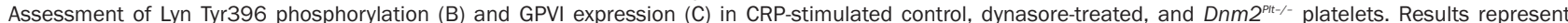
mean \pm standard error of mean (SEM) of 3-4 independent experiments, and are compared statistically to control $(* P<0.05 ; * * P<0.01 ; * * * P<0.001)$. 
The decreased GPIb $\alpha$ surface expression was due to internalization, and not to shedding, as total GPIb $\alpha$ expression was maintained during the course of the experiment, as shown by immunoblot analysis (Figure 3C). Taken together, the data show that DNM2 specifically regulates GPVI signaling, rather than GPIb $\alpha$ downregulation.

\section{Impaired $\alpha$-granule secretion and integrin $\alpha \operatorname{llb} \beta 3$ activation in CRP-stimulated dynasore-treated and Dnm2 $2^{\text {Plt-/ }}$ platelets}

Following activation by collagen or soluble agonists, platelets secrete their granule contents and activate their surface integrin $\alpha \operatorname{Ib} \beta 3$ in order to recruit circulating platelets and mediate platelet aggregation, respectively. The significance of DNM2 in these platelet hemostatic processes was assessed by flow cytometry (Figure 4). Control platelets, dynasore-treated platelets, and Dnm $2^{\text {Plt- }-}$ platelets were activated with CRP (Figure 4A and C) or thrombin (Figure 4B and D), and analyzed for P-selectin (CD62P) expression, a marker for $\alpha$-granule secretion (Figure 4A and B), and binding of fluorescently-labeled fibrinogen, a marker for integrin $\alpha \mathrm{IIb} \beta 3$ activation (Figure 4C and D). ${ }^{19}$ Both CRP and thrombin induced a concentration-dependent increase of $\alpha$-granule secretion and integrin $\alpha \mathrm{IIb} \beta 3$ activation in control platelets, reaching about $80 \%$ of platelets expressing CD62P or binding fibrinogen with $25 \mu \mathrm{g} / \mathrm{mL}$ CRP or $0.25 \mathrm{U} / \mathrm{mL}$ thrombin, respectively. Dynasore treatment resulted in a significant decrease in platelet responses to CRP, as only $30-40 \%$ platelets expressed CD62P and bound fibrinogen with $50 \mu \mathrm{g} / \mathrm{mL}$ CRP. By contrast, platelet responses to thrombin were not significantly affected by dynasore treatment. CRP-dependent CD62P expression and fibrinogen binding were completely abolished in $D n m 2^{P_{t-1}}$ platelets and only about
$20 \%$ expressed CD62P and bound fibrinogen in response to $0.5 \mathrm{U} / \mathrm{mL}$ thrombin.

\section{Altered spreading of dynasore-treated and Dnm2 $2^{\text {Plt-- }}$ platelets}

Following activation, platelets rapidly change shape from resting disc-like entities to morphologically distinct forms, first by rounding, then by extending finger-like filopodia and spreading thin sheet-like lamellipodia. ${ }^{30}$ The significance of DNM2 in platelet spreading was examined (Figure 5). Control platelets, dynasore-treated, and $D_{n m} 2^{P l-1-}$ platelets were activated with either $1 \mu \mathrm{g} / \mathrm{mL}$ CRP or $0.01 \mathrm{U} / \mathrm{mL}$ thrombin and allowed to adhere onto immobilized fibrinogen. In control platelets, stimulation with CRP or thrombin resulted in filopodia extension and lamellipodia spreading, as evidenced by phalloidin staining, a marker for polymerized actin, with the greatest difference being more angular or rounded appearance, respectively (Figure 5A). Treatment with dynasore mitigated lamellipodia formation in CRP-stimulated platelets (Figure 5B), and to a lesser, non-statistically significant degree in thrombin-stimulated platelets (Figure 5C), although it did not prevent filopodia growth.

$D n m 2^{P t-1-}$ platelets displayed great heterogeneity in shape change with either agonist (Figure 5A), wherein spread platelet surface area varied between below control levels or up to a 5 -fold increase in size following stimulation, reflecting the increased size of these platelets. $D n m 2^{P l-1}$ platelets revealed extreme irregularity in their cytoskeletal and overall morphological arrangement, consistent with altered spreading capacity.

\section{Absence of fibrinogen in Dnm2 $2^{\text {Ptt- }}$ platelets}

The fibrinogen content of platelet $\alpha$-granules derives from the integrin $\alpha \operatorname{Ilb} \beta 3$-dependent uptake of plasma-
A

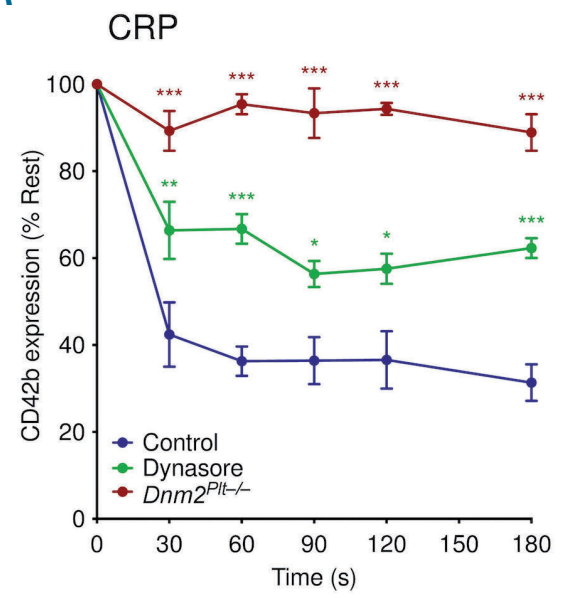

C

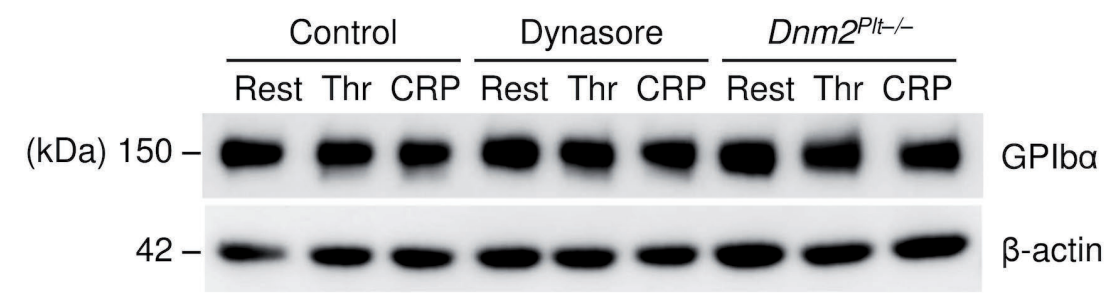

B Thrombin

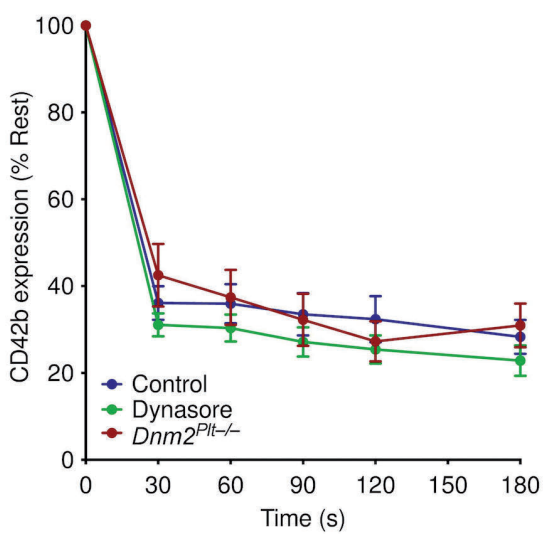

$\beta$-actin
Figure 3. Impaired GPIb $\alpha$ downregulation in CRP-stimulated dynasore-treated and Dnm2 $2^{\text {PIt-/- }}$ platelets. Control platelets, platelets treated with $100 \mu \mathrm{M}$ dynasore, and $\mathrm{Dnm} 2^{\mathrm{Pt}-\mathrm{\gamma}-}$ platelets were activated for 3 minutes (min) at $37^{\circ} \mathrm{C}$ with $25 \mathrm{\mu g} / \mathrm{mL}$ CRP (A) or $0.1 \mathrm{U} / \mathrm{ml}$ thrombin (B), incubated with FITC labeled anti-mouse CD42b antibody, and analyzed by flow cytometry. Results are expressed as percentage of CD42b expression at rest, represent mean \pm standard error of mean (SEM) of three independent experiments, and are compared statistically to control $(* P<0.05 ; * * P<0.01 ; * * * P<0.001) .(\mathrm{C})$ Control, dynasore-treated, and $\mathrm{Dnm} 2^{\text {Ptt-/ }}$ platelets were activated or not with $0.1 \mathrm{U} / \mathrm{mL}$ thrombin or $25 \mathrm{ug} / \mathrm{mL}$ CRP for $3 \mathrm{~min}$ at $37^{\circ} \mathrm{C}$ as indicated. Platelet lysates were subjected to SDSPAGE and probed for GPIb $\alpha$ and $\beta$-actin as loading control, as indicated. Results are representative of three independent experiments. 
derived fibrinogen. ${ }^{31,32}$ To evaluate the contribution of DNM2-dependent RME in the process, the fibrinogen content of Dnm2 $2^{P t-1}$ platelets was compared to that of $\mathrm{vWF}$, which is synthesized by $\mathrm{MK}$ and is also stored in platelet $\alpha$-granules (Figure 6A). ${ }^{33}$ Immunoblot analysis showed severe fibrinogen reduction in $D n m 2^{P l t--}$ platelet lysates, but normal expression of vWF. Quantification of the immunoblots using purified mouse fibrinogen as standard revealed that $10^{6} \mathrm{Dnm} 2^{P l t-}$ platelets contained $71 \pm 6$ ng fibrinogen, compared to $333 \pm 27 \mathrm{ng}$ in $10^{6}$ control platelets ( $n=3$ in each group) $(P=0.0007)$, a $79 \%$ decrease (Figure 6B).

The fibrinogen content of control and $D n m 2^{P l-1}$ platelets was further evaluated by structured illumination microscopy and compared to that of the allb subunit (CD41) of its receptor, the integrin $\alpha I$ Ilb $\beta 3$ (Figure 6C, top panels). In control platelets fibrinogen was observed in large puncta, consistent with its presence in $\alpha$-granules. ${ }^{33}$ By contrast, Dnm2 $2^{P l t-}$ platelets had severely reduced fibrinogen content, with about $90 \%$ of $D n m 2^{P l t-}$ platelets presenting barely detectable fibrinogen positive $\alpha$-granules. CD41 resided on the platelet surface and in small vesicles or granules within platelets, independent of DNM2 expression, consistent with the association of the integrin $\alpha I$ Ilb $\beta 3$ with multiple intracellular platelet compartments that include $\alpha$-granules and the open canalicu- lar system. ${ }^{34}$ By contrast, vWF was normally packaged in Dnm2 $2^{P t-/}$ platelets (Figure 6C, bottom panels). Taken together, the data show that integrin $\alpha \operatorname{Ilb} \beta 3$-dependent uptake of plasma-derived fibrinogen requires DNM2dependent RME.

\section{Platelet endocytic and endosomal components}

Thin-section electron microscopy studies have subdivided RME into clathrin- and caveolae-mediated endocytosis (CME and CavME, respectively). ${ }^{1} \mathrm{CME}$ is found in virtually all cells and requires cargo receptor binding to clathrin-associated adaptor protein 2 complexes to form clathrin-coated vesicles. ${ }^{35}$ Caveolae are invaginated lipid rafts rich in cholesterol, sphingolipids, and scaffolding proteins called caveolins and cavins that are found in many mammalian cell types. ${ }^{36}$ Platelet endocytic and endosomal components were investigated in the presence or absence of DNM2 (Figure 6A). Platelets contained clathrin heavy chain required for $\mathrm{CME}$ and its expression was increased in Dnm2 $2^{P h-1}$ platelets. Cavin 2 (also known as SDPR, PSp68) was detected in platelets, but not caveolin 1, which is required for CavME. Ruling out poor antibody reactivity, a strong caveolin 1 signal was observed at the expected molecular weight of $21 \mathrm{kDa}$ with mouse lung tissue lysates (data not shown). ${ }^{37}$

As an additional control and because cavin 2 associates

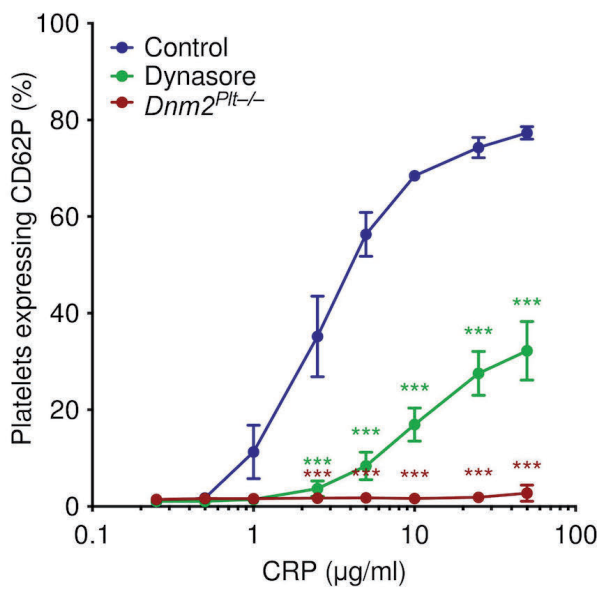

C

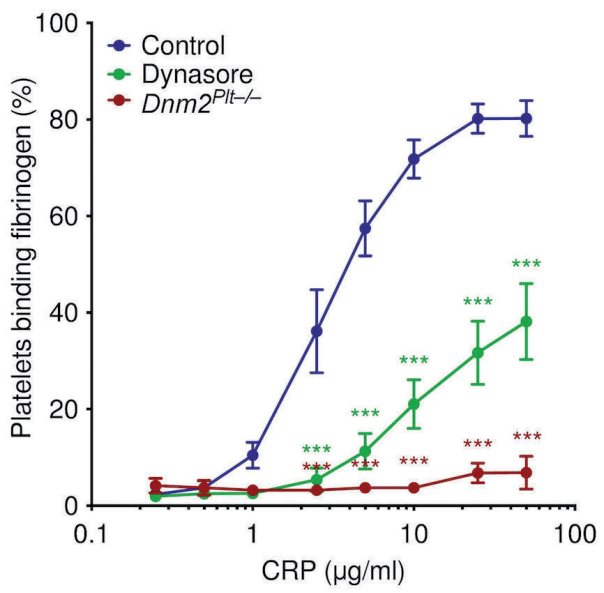

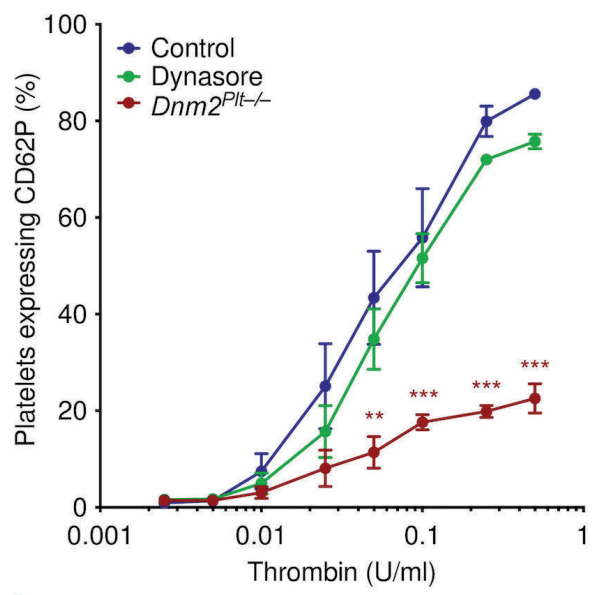

D

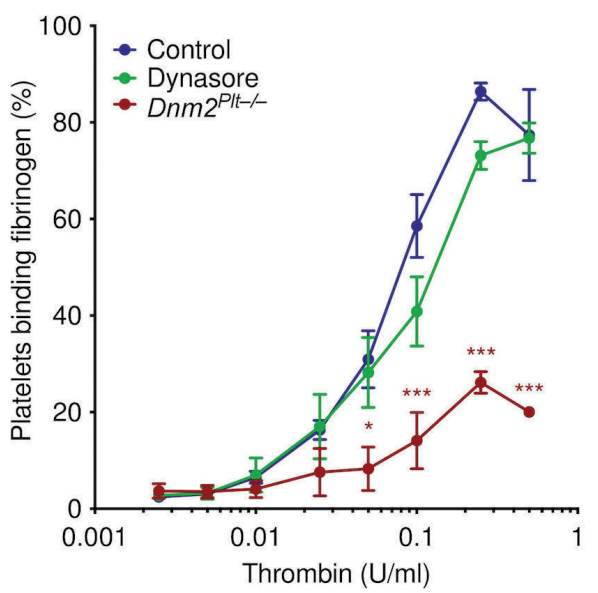

Figure 4. Hemostatic defects of CRP-stimulated dynasoretreated and Dnm2 $2^{\text {Plt- } / \mathrm{A}}$ platelets. Control platelets, platelets treated with $100 \mu \mathrm{M}$ dynasore, and Dnm2 $2^{\mathrm{Pt}-/-}$ platelets were activated for 2 min at $37^{\circ} \mathrm{C}$ with CRP (A and C) or thrombin (B and $D)$ as indicated. Platelets were then incubated with FITC-labeled anti-mouse CD62P antibody (A and B) or Oregon green 488-labeled fibrinogen (C and D) and analyzed by flow cytometry. Results are expressed as percentage of positive platelets, represent mean \pm standard error of mean (SEM) of 3-6 independent experiments, and are compared statistically to control $(* P<0.05 ; \quad * * P<0.01$; $* * * P<0.001$ ). 
with insoluble lipid rafts in cells expressing caveolin $1,{ }^{38}$ the association of cavin 2 with detergent-resistant platelet lipid rafts was investigated using a sucrose gradient in human platelet lysates (Figure 6D), which also lack caveolin 1 (data now shown). Cavin 2 did not associate with the insoluble sucrose gradient fractions rich in GM1 ganglioside and flotillin 1. Taken together, the data show that platelets contained the endocytic machinery required for CME, but not for CavME.

Early, late, and recycling endosomal compartments are distinguished by their association with specific members of the Rab family of small GTPases. Platelets contained Rab5 (early), Rab7 (late), and Rab11 (recycling), as described previously, ${ }^{33,39}$ and their expression levels were not affected by the lack of DNM2 (Figure 6A).

\section{Discussion}

The cellular mechanisms and proteins regulating platelet and MK RME are poorly understood. ${ }^{39}$ Here, using both pharmacological and genetic approaches, we described the role of the endocytic GTPase DNM2 in intracellular signaling via the collagen receptor GPVI and platelet hemostatic function.

In control platelets, ligation of the collagen receptor GPVI by its soluble agonist CRP induced an increase in protein tyrosine phosphorylation, including that of the proximal protein tyrosine kinase Lyn on its activating residue Tyr396, and a decrease in GPVI expression. Following dynasore treatment, phosphorylation of Lyn Tyr396 was attenuated and GPVI expression was maintained. Recent studies have shown that common dynamin inhibitors, such as dynasore and Dyngo-4a, not only inhibit dynamin GTPase activity, but also disrupt the organization of cholesterol-rich membrane rafts in a dynamin-independent manner. ${ }^{40,41}$ Dynasore-treated platelets elicited defects in GPIb $\alpha$ downregulation, $\alpha$-granule secretion, integrin $\alpha \operatorname{Ilb} \beta 3$ activation, and spreading onto fibrinogen when stimulated via GPVI, but not by thrombin. By contrast, the cholesterol-lowering reagent, methyl- $\beta$-cyclodextrin, inhibits GPVI signaling, as well as platelet responses to the G-protein-coupled receptor agonists, thrombin and $\mathrm{ADP} .{ }^{42,43}$ Hence, the data argue

A
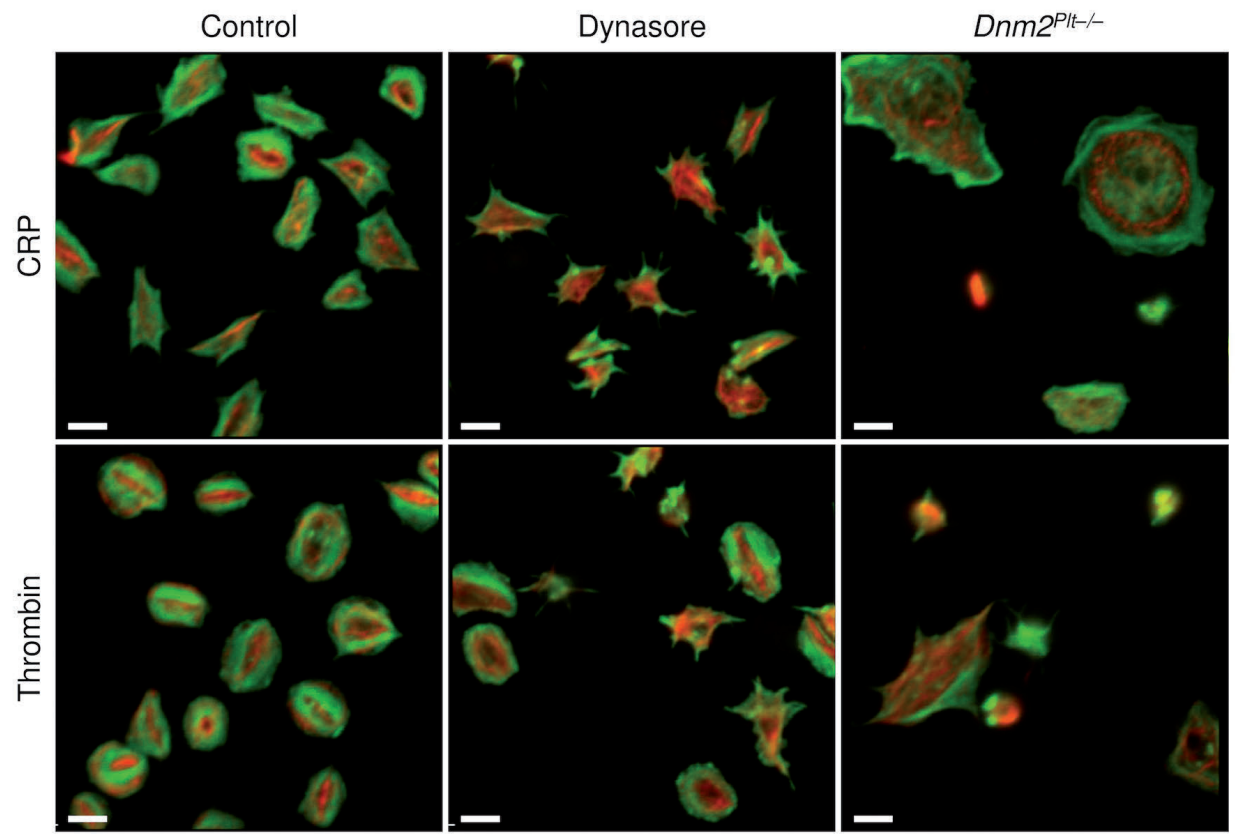

Phalloidin $\beta$-tubulin

B

CRP

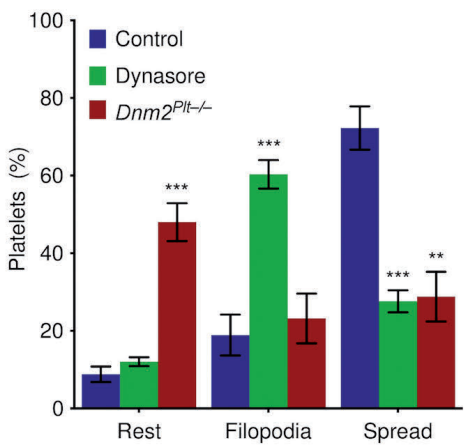

C

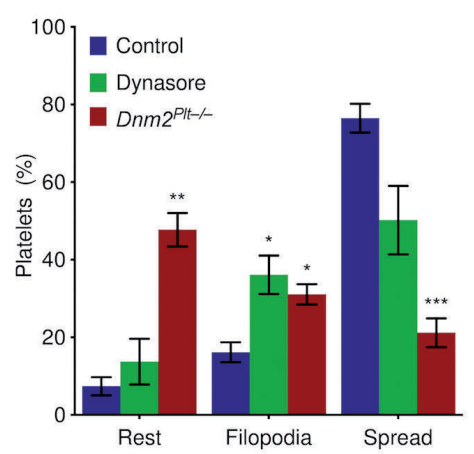

Figure 5. Altered spreading of CRP-stimulated dynasore-treated and Dnm2 $2^{\mathrm{Pt}-/-}$ platelets. (A) Control platelets, platelets treated with $100 \mu \mathrm{M}$ dynasore, and $D n m 2^{\text {Ptt }-/-}$ platelets were activated with $1 \mu \mathrm{g} / \mathrm{mL}$ CRP or $0.01 \mathrm{U} / \mathrm{mL}$ thrombin and spread onto fibrinogen-coated coverslips for 30 minutes (min) as indicated. Fixed platelets were stained for polymerized actin (phalloidin; green) and $\beta$-tubulin (red) and analyzed by confocal microscopy. Images are representative of at least three independent experiments. Scale bars, $3 \mu \mathrm{m}$. (B) Assessment of platelet spreading in response to $1 \mu \mathrm{g} / \mathrm{mL}$ CRP. Total platelets scored were 374 control, 275 dynasore-treated, and 187 Dnm2 $2^{\text {Ptt-/ }}$. (C) Assessment of platelet spreading in response to $0.01 \mathrm{U} / \mathrm{mL}$ thrombin. Total platelets scored were 298 control, 226 dynasore-treated, and $192 \mathrm{Dnm}^{\text {Plt }-/-}(* P<0.05 ; * * P<0.01$; $* * * P<0.001)$. 
against membrane raft disruption and indicate that DNM2 plays a proximal role in GPVI signaling.

The positive role of DNM2 in GPVI signaling contrasts with its commonly reported function in attenuating receptor signaling. Lack of DNM2-dependent RME enhances responses to thrombopoietin in platelets and $\mathrm{MK}$ and to epidermal growth factor and interleukins 5 and 7 in other cells. ${ }^{9-12}$ Dynasore treatment also inhibits the desensitiza- tion of the purinergic receptors $\mathrm{P} 2 \mathrm{Y} 1$ and $\mathrm{P} 2 \mathrm{Y} 12$ in human platelets. ${ }^{13}$ Thus, DNM2 differentially regulates signaling depending on the receptor it is linked to. The GPVI-associated FcR $\gamma$-chain contains two putative endocytic YxxL motifs that are present within its immunoreceptor tyrosine-based activation motif. Whether these motifs recruit the endocytic machinery necessary to down-regulate GPVI is unclear, as their mutation in mouse platelets abol-
A

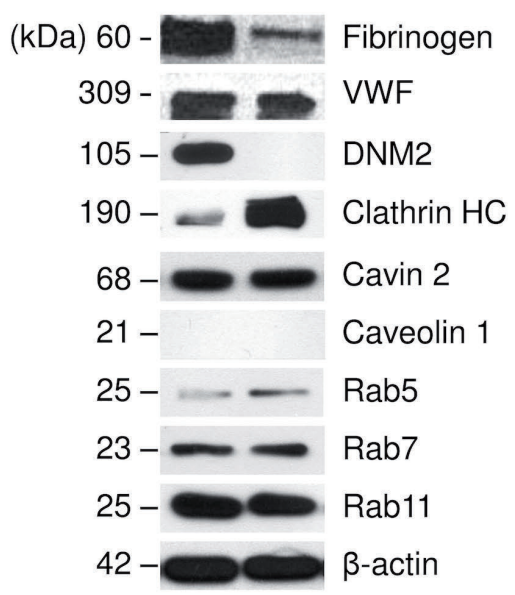

B

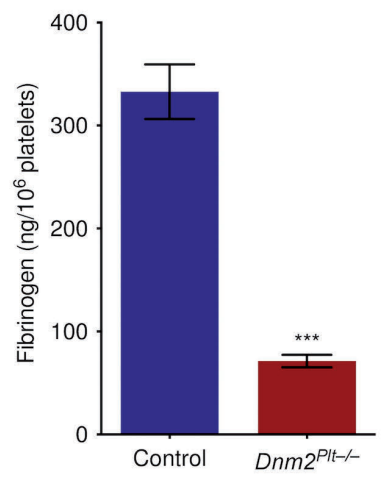

C

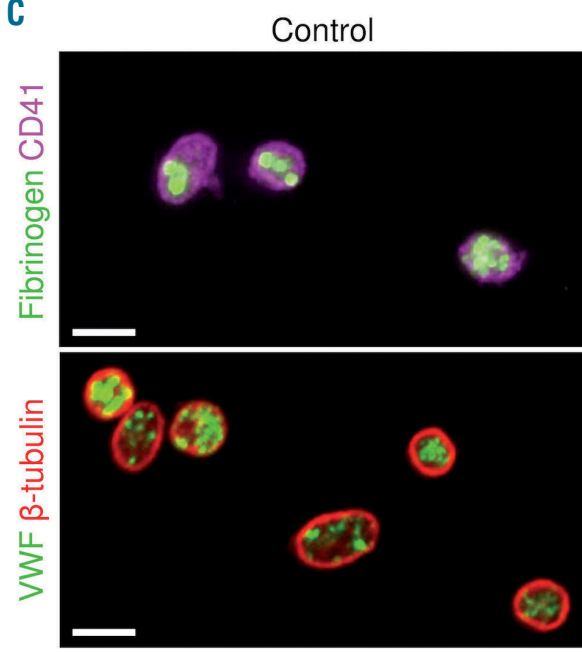

Dnm2Plt--

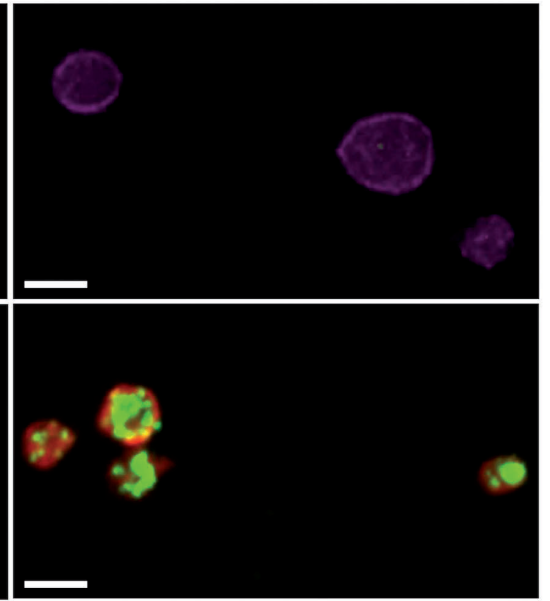

D

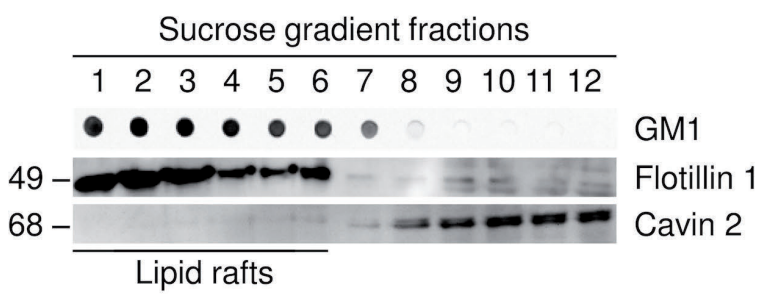

Figure 6. Cargo, endocytic, and endosomal proteins in Dnm2 $2^{\mathrm{Plt}-/-}$ platelets. (A) Control and Dnm2 $2^{\mathrm{Pt}-/-}$ platelet lysates corresponding to $2 \mu \mathrm{g}$ of protein were subjected to SDS-PAGE and probed for cargo, endocytic, and endosomal proteins, and $\beta$-actin as loading control, as indicated. Results are representative of three independent experiments. HC: heavy chain. (B) The fibrinogen content of control and Dnm2 $2^{\text {Ptt- }-~ p l a t e l e t s ~ w a s ~ e v a l u a t e d ~ b y ~ i m m u n o b l o t ~ a n a l y s i s ~ u s i n g ~ p u r i f i e d ~ m o u s e ~ f i b r i n o g e n ~}$ as standard. Results are expressed as $\mathrm{ng} / 10^{6}$ platelets and represent mean \pm standard error of mean (SEM) of three independent experiments $(* * * P=0.0007)$. (C) Structured illumination microscopy analysis of fibrinogen (green) and CD41 (magenta; top panels) and confocal microscopy analysis of vWF (green) and $\beta$-tubulin (red; bottom panels) in control and Dnm2 ${ }^{\text {Ptt- }-~}$ platelets. Scale bars, 3 um. (D) Sucrose density fractions of human platelet lysates were dot-blotted and probed with HRP-conjugated cholera toxin B subunit to detect GM1 ganglioside or immunoblotted for flotillin 1 and cavin 2. 
ishes both GPVI signaling and internalization. ${ }^{44}$ Besides its role in membrane fission during RME, DNM2 can also serve as a scaffolding protein for signaling intermediates. ${ }^{2}$ In $\mathrm{T}$ cells, DNM2 directly interacts with the guanine nucleotide exchange factor Vav1 to regulate activation of PLC- $\gamma 1$ and the accumulation of cortical actin at sites of T-cell receptor activation, thereby regulating T-cell receptor signaling. ${ }^{45}$ Vav1 and Vav3 play critical but redundant roles in the activation of PLC- $\gamma 2$ downstream of GPVI, ${ }^{46}$ and clustering of GPVI dimers, the mechanism of which depends on a dynamic actin cytoskeleton, contributes to GPVI signaling. ${ }^{47}$ It is, therefore, tempting to speculate that platelet DNM2 serves as a scaffolding protein for signaling intermediates and/or actin-regulatory proteins downstream of GPVI.

$D n m 2^{P l-1}$ mice had a severe bleeding diathesis, which was intrinsic to platelets as Dnm2 deletion under control of the Pf4 promoter is specific to the platelet lineage. ${ }^{9}$ Consistently, Dnm $2^{P t-1}$ platelets adhered poorly to collagen under arterial shear rates and were depleted of fibrinogen. Further, $\alpha$-granule secretion, integrin $\alpha$ Ilb $\beta 3$ activation, and spreading onto fibrinogen were markedly reduced in Dnm $2^{P l_{l-}-}$ platelets stimulated through GPVI or with thrombin. The lack of GPVI signaling is likely explained by the profound deficit in GPVI expression. ${ }^{9}$ Whether this deficit is due to decreased GPVI synthesis in $D n m 2^{P l t-1} \mathrm{MK}$, increased internalization and degradation, or ADAM10-mediated extracellular domain shedding is unclear. The differences between the pharmacological and genetic approaches indicate that either dynasore treatment does not completely inhibit platelet DNM2 GTPase activity or Dnm2 $2^{P l-l}$ platelets acquire defects during production affecting their functional responses. Because RME is a critical component of cellular cholesterol homeostasis, ${ }^{1}$ it is possible that Dnm2 genetic deletion impacts cell membrane composition and lipid raft organization, thereby affecting signaling in cholesterol-rich membrane domains. While the tail bleeding time in mice is largely unaffected by severe reduction of platelet count or lack of GPVI, ${ }^{48,49}$ it cannot be excluded that the macrothrombocytopenia of $D n m 2^{P_{t h-}}$ mice combined with the profound deficit in GPVI expression contributes to the bleeding diathesis.

The severe reduction in fibrinogen content of $D n m 2^{P l t--}$ platelets is consistent with impaired RME and a role for DNM2 downstream of integrin $\alpha \operatorname{Il} \beta \beta 3$ function as plasma fibrinogen is taken up by platelets and $\mathrm{MK}$ in an integrin $\alpha I I b \beta 3$-mediated manner. ${ }^{31,32}$ Beside fibrinogen, platelets and $\mathrm{MK}$ take up and store in their $\alpha$-granules a long list of plasma proteins such as coagulation factor $\mathrm{V}$ and regulators of angiogenesis. ${ }^{50,51}$ While the hypothesis was not tested here, endocytosed proteins are expected to be absent in Dnm $2^{P l t-1}$ platelets due to defective RME, affecting other biological processes aside from hemostasis.

Platelets contained major endocytic and endosomal proteins such as clathrin and Rab GTPases. ${ }^{33,39}$ The increased expression of clathrin heavy chain in Dnm2 $2^{P l-\alpha}$ platelets likely reflects the accumulation of clathrin-coated vesicles observed in the demarcation membrane system of Dnm2 $2^{P l-/}$ MK. ${ }^{9}$ Caveolin 1 was not detected in platelets, consistent with mRNA and protein profiling, ${ }^{14,15,17}$ and cavin 2, a detergent-insoluble caveolae marker in cells expressing caveolin $1,^{38}$ remained soluble following sucrose gradient of human platelet lysates. While cavin 2 is abundantly expressed in platelets, ${ }^{14,15,17}$ where it was originally characterized, ${ }^{52}$ its role in the absence of caveolin 1 is unclear. Taken together, the observations show that $\mathrm{CME}$ is the primary mechanism for $\mathrm{RME}$ in platelets. Consistently, fibrinogen uptake involves the recruitment of clathrin-associated adaptor protein 2 complexes to the $\beta 3$ subunit of the integrin $\alpha \operatorname{Ilb} \beta 3$ via clathrin adaptor proteins such as Dab2 and Numb. ${ }^{53,54}$ After its uptake by CME and transport via the early (Rab5) and late (Rab7) endosome, fibrinogen is retained within $\alpha$-granules by mechanisms dependent on NBEAL2, mutated in gray platelet syndrome. ${ }^{33}$ The remaining fibrinogen content of $D_{n m} 2^{P t-1-}$ platelets is likely associated with the plasma membrane or trapped in the open canalicular system.

In conclusion, our work provides pharmacological and genetic evidence for a role of DNM2 in GPVI signaling and platelet hemostatic function. DNM2 regulates signaling events downstream of the collagen receptor GPVI, including the activation of the proximal tyrosine kinase Lyn, and is required for the integrin $\alpha \mathrm{IIb} \beta 3$-mediated accumulation of plasma fibrinogen into $\alpha$-granules. Our data also show that DNM2 does not contribute to GPIba downregulation, as dynasore-treated platelets and $D n m 2^{P t-1}$ platelets down-regulated GPIb $\alpha$ normally in response to thrombin. Whether DNM2 is a reasonable target for antithrombotic therapies remains to be determined.

\section{Acknowledgments}

The authors would like to thank Emily Legan and Scott Wood for technical assistance and Drs. Harry Heijnen, Karin Hoffmeister, and Walter Kahr for helpful discussions. This work was supported by the American Society of Hematology Foundation and National Institutes of Health R01 grant HL126743 (HF).

\section{References}

1. Doherty GJ, McMahon HT. Mechanisms of endocytosis. Annu Rev Biochem. 2009;78:857-902

2. Ferguson SM, De Camilli P. Dynamin, a membrane-remodelling GTPase. Nat Rev Mol Cell Biol. 2012;13(2):75-88.

3. Züchner S, Noureddine M, Kennerson M, et al. Mutations in the pleckstrin homology domain of dynamin 2 cause dominant intermediate Charcot-Marie-Tooth disease. Nat Genet. 2005;37(3):289-294.
4. Bitoun M, Maugenre S, Jeannet PY, et al. Mutations in dynamin 2 cause dominant centronuclear myopathy. Nat Genet. 2005;37(11):1207-1209

5. Zhang J, Ding L, Holmfeldt L, et al. The genetic basis of early $\mathrm{T}$-cell precursor acute lymphoblastic leukaemia. Nature. 2012;481(7380):157-163.

6. Ferguson SM, Raimondi A, Paradise S, et al. Coordinated actions of actin and BAR proteins upstream of dynamin at endocytic clathrin-coated pits. Dev Cell. 2009;17(6): 811-822.

7. Ferguson SM, Brasnjo G, Hayashi M, et al
A selective activity-dependent requirement for dynamin 1 in synaptic vesicle endocytosis. Science. 2007;316(5824):570-574.

8. Raimondi A, Ferguson SM, Lou X, et al. Overlapping role of dynamin isoforms in synaptic vesicle endocytosis. Neuron. 2011;70(6):1100-1114.

9. Bender M, Giannini S, Grozovsky R, et al. Dynamin 2-dependent endocytosis is required for normal megakaryocyte development in mice. Blood. 2015;125(6):10141024.

10. Gorska MM, Cen O, Liang Q, Stafford SJ, Alam R. Differential regulation of inter- 
leukin 5 -stimulated signaling pathways by dynamin. J Biol Chem. 2006;281(20):1442914439.

11. Sousa LP, Lax I, Shen H, Ferguson SM, De Camilli P, Schlessinger J. Suppression of EGFR endocytosis by dynamin depletion reveals that EGFR signaling occurs primarily at the plasma membrane. Proc Natl Acad Sci U S A. 2012;109(12):4419-4424.

12. Tremblay CS, Brown FC, Collett M, et al. Loss-of-function mutations of Dynamin 2 promote T-ALL by enhancing IL-7 signalling. Leukemia. 2016;30(10):1993-2001.

13. Mundell SJ, Barton JF, Mayo-Martin MB, Hardy AR, Poole AW. Rapid resensitization of purinergic receptor function in human platelets. J Thromb Haemost. 2008;6(8): 1393-1404.

14. Rowley JW, Oler AJ, Tolley ND, et al. Genome-wide RNA-seq analysis of human and mouse platelet transcriptomes. Blood. 2011;118(14):e101-111.

15. Burkhart JM, Vaudel M, Gambaryan S, et al. The first comprehensive and quantitative analysis of human platelet protein composition allows the comparative analysis of structural and functional pathways. Blood. 2012;120(15):e73-82.

16. Nürnberg ST, Rendon A, Smethurst PA, et al. A GWAS sequence variant for platelet volume marks an alternative DNM3 promoter in megakaryocytes near a MEIS1 binding site. Blood. 2012;120(24):48594868.

17. Zeiler M, Moser M, Mann M. Copy number analysis of the murine platelet proteome spanning the complete abundance range. Mol Cell Proteomics. 2014;13(12): 3435-3445

18. Lorenz V, Ramsey H, Liu ZJ, et al. Developmental Stage-Specific Manifestations of Absent TPO/c-MPL Signalling in Newborn Mice. Thromb Haemost. 2017;117(12):2322-2333.

19. Falet $\mathrm{H}$, Pollitt AY, Begonja AJ, et al. A novel interaction between FlnA and Syk regulates platelet ITAM-mediated receptor signaling and function. J Exp Med. 2010;207(9):19671979.

20. Kanaji T, Kanaji S, Montgomery RR, Patel SB, Newman PJ. Platelet hyperreactivity explains the bleeding abnormality and macrothrombocytopenia in a murine model of Sitosterolemia. Blood. 2013;122(15):2732-2742.

21. Koseoglu S, Dilks JR, Peters CG, et al. Dynamin-related protein-1 controls fusion pore dynamics during platelet granule exocytosis. Arterioscler Thromb Vasc Biol. 2013;33(3):481-488.

22. Jones CI, Sage T, Moraes LA, et al. Platelet endothelial cell adhesion molecule-1 inhibits platelet response to thrombin and von Willebrand factor by regulating the internalization of glycoprotein Ib via AKT/glycogen synthase kinase-3/dynamin and integrin alphaIIbbeta3. Arterioscler Thromb Vasc Biol. 2014;34(9):1968-1976.

23. Gao W, Shi P, Chen X, et al. Clathrin-mediated integrin alphallbbeta3 trafficking controls platelet spreading. Platelets. 2018;29(6):617-621.

24. Munday AD, Gaus K, Lopez JA. The platelet glycoprotein Ib-IX-V complex anchors lipid rafts to the membrane skeleton: implications for activation-dependent cytoskeletal translocation of signaling molecules. J Thromb Haemost. 2010;8(1):163-172.

25. Begonja AJ, Pluthero FG, Suphamungmee W, et al. FlnA binding to PACSIN2 F-BAR domain regulates membrane tubulation in megakaryocytes and platelets. Blood. 2015;126(1):80-88

26. Nieswandt B, Watson SP. Platelet-collagen interaction: is GPVI the central receptor Blood. 2003;102(2):449-461.

27. Watson SP, Auger JM, McCarty OJ, Pearce AC. GPVI and integrin alphallb beta3 signaling in platelets. J Thromb Haemost. 2005;3(8):1752-1762.

28. Ezumi Y, Shindoh K, Tsuji M, Takayama H. Physical and functional association of the Src family kinases Fyn and Lyn with the collagen receptor glycoprotein VI-Fc receptor gamma chain complex on human platelets. J Exp Med. 1998;188(2):267-276.

29. Michelson AD, Barnard MR. Thrombininduced changes in platelet membrane glycoproteins Ib, IX, and IIb-IIIa complex. Blood. 1987;70(5):1673-1678

30. Falet $\mathrm{H}$. Anatomy of the Platelet Cytoskeleton. In: Gresele P, Kleiman NS, López JA, Page CP, eds. Platelets in Thrombotic and Non-Thrombotic Disorders: Pathophysiology, Pharmacology and Therapeutics: an Update: Springer; 2017:139-156.

31. Harrison P, Wilbourn B, Debili N, et al. Uptake of plasma fibrinogen into the alpha granules of human megakaryocytes and platelets. J Clin Invest. 1989;84(4):1320-1324

32. Handagama P, Scarborough RM, Shuman MA, Bainton DF. Endocytosis of fibrinogen into megakaryocyte and platelet alphagranules is mediated by alpha IIb beta 3 (glycoprotein IIb-IIIa). Blood. 1993;82(1): 135-138.

33. Lo RW, Li L, Leung R, Pluthero FG, Kahr WHA. NBEAL2 (Neurobeachin-Like 2) Is Required for Retention of Cargo Proteins by alpha-Granules During Their Production by Megakaryocytes. Arterioscler Thromb Vasc Biol. 2018;38(10):2435-2447

34. Cramer EM, Savidge GF, Vainchenker W, et al. Alpha-granule pool of glycoprotein IIbIIIa in normal and pathologic platelets and megakaryocytes. Blood. 1990;75(6):12201227.

35. Kaksonen M, Roux A. Mechanisms of clathrin-mediated endocytosis. Nat Rev Mol Cell Biol. 2018;19(5):313-326.

36. Parton RG, del Pozo MA. Caveolae as plasma membrane sensors, protectors and organizers. Nat Rev Mol Cell Biol. 2013;14(2):98-112.

37. Guo YH, Hernandez I, Isermann B, et al. Caveolin-1-dependent apoptosis induced by fibrin degradation products. Blood 2009;113(18):4431-4439.

38. Hansen CG, Bright NA, Howard G Nichols BJ. SDPR induces membrane curvature and functions in the formation of cavelae. Nat Cell Biol. 2009;11(7):807-814

39. Banerjee M, Whiteheart SW. The ins and outs of endocytic trafficking in platelet functions. Curr Opin Hematol.
2017;24(5):467-474

40. Park R, Shen H, Liu L, Liu X, Ferguson SM De Camilli P. Dynamin triple knockout cells reveal off target effects of commonly used dynamin inhibitors. J Cell Sci. 2013:126(22):5305-5312.

41. Preta G, Cronin JG, Sheldon IM. Dynasore - not just a dynamin inhibitor. Cell Commun Signal. 2015;13:24.

42. Ezumi Y, Kodama K, Uchiyama T, Takayama H. Constitutive and functional association of the platelet collagen receptor glycoprotein VI-Fc receptor gamma-chain complex with membrane rafts. Blood. 2002:99(9):3250-3255

43. Quinton TM, Kim S, Jin J, Kunapuli SP Lipid rafts are required in Galpha(i) signaling downstream of the P2Y12 receptor during ADP-mediated platelet activation. Thromb Haemost. 2005;3(5):1036-1041.

44. Rabie T, Varga-Szabo D, Bender M, et al. Diverging signaling events control the pathway of GPVI down-regulation in vivo. Blood. 2007:110(2):529-535.

45. Gomez TS, Hamann MJ, McCarney S, et al Dynamin 2 regulates $T$ cell activation by controlling actin polymerization at the immunological synapse. Nat Immunol. 2005;6(3):261-270.

46. Pearce AC, Senis YA, Billadeau DD, Turner M, Watson SP, Vigorito E. Vav1 and vav3 have critical but redundant roles in mediating platelet activation by collagen. J Biol Chem. 2004;279(52):53955-53962.

47. Poulter NS, Pollitt AY, Owen DM, et al Clustering of glycoprotein VI (GPVI) dimers upon adhesion to collagen as a mechanism to regulate GPVI signaling in platelets. J Thromb Haemost. 2017;15(3): 549-564.

48. Kato K, Kanaji T, Russell S, et al. The contribution of glycoprotein VI to stable platelet adhesion and thrombus formation illustrated by targeted gene deletion. Blood. 2003;102(5):1701-1707.

49. Morowski M, Vogtle T, Kraft P, Kleinschnitz C, Stoll G, Nieswandt B. Only severe thrombocytopenia results in bleeding and defective thrombus formation in mice. Blood. 2013;121(24):4938-4947.

50. Gould WR, Simioni P, Silveira JR, Tormene D, Kalafatis M, Tracy PB. Megakaryocytes endocytose and subsequently modify human factor $\mathrm{V}$ in vivo to form the entire pool of a unique platelet-derived cofactor. J Thromb Haemost. 2005;3(3):450-456.

51. Klement GL, Yip TT, Cassiola F, et al. Platelets actively sequester angiogenesis regulators. Blood. 2009;113(12):2835-2842.

52. Burgener R, Wolf M, Ganz T, Baggiolini M. Purification and characterization of a major phosphatidylserine-binding phosphoprotein from human platelets. Biochem J. 1990;269(3):729-734

53. Tsai HJ, Huang CL, Chang YW, et al Disabled-2 is required for efficient hemostasis and platelet activation by thrombin in mice. Arterioscler Thromb Vasc Biol. 2014:34(11):2404-2412.

54. Yu CH, Rafiq NB, Cao F, et al. Integrinbeta3 clusters recruit clathrin-mediated endocytic machinery in the absence of traction force. Nat Commun. 2015;6:8672. 